\title{
Flexible, All-Organic Chemiresistor for Detecting Chemically Aggressive Vapors
}

\author{
Srikanth Ammu, Vineet Dua, Srikanth Rao Agnihotra, Sumedh P. Surwade, Akshay Phulgirkar, \\ Sanjaykumar Patel, and Sanjeev K. Manohar* \\ Department of Chemical Engineering, University of Massachusetts Lowell, Lowell, Massachusetts 01854, United States
}

\section{Supporting Information}

ABSTRACT: Chemiresistors made of thin films of singlewalled carbon nanotube (CNT) bundles on cellulosics (paper and cloth) can detect aggressive oxidizing vapors such as nitrogen dioxide and chlorine at 250 and $500 \mathrm{ppb}$, respectively, at room temperature in ambient air without the aid of a vapor concentrator. Inkjet-printed films of CNTs on $100 \%$ acid-free paper are significantly more robust than dip-coated films on plastic substrates. Performance attributes include low sensor-to-sensor variation, spontaneous signal recovery, negligible baseline drift, and the ability to bend the sensors to a crease without loss of sensor performance.

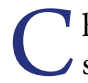
hemiresistor vapor sensors based on thin films of highsurface-area organics such as carbon nanotubes (CNTs) ${ }^{1-5}$ graphene, ${ }^{8-9}$ and conducting polymers ${ }^{10,11}$ offer significant advantages over conventional metal oxide-based chemiresistors in terms of sensitivity, selectivity, ease of use, and room-temperature operability. ${ }^{12}$ However, detection of highly toxic chemical warfare agents (CWAs) such as $\mathrm{NO}_{2}, \mathrm{Cl}_{2}$, $\mathrm{SO}_{2}$, etc., remains a challenge because they can irreversibly react with thin organic films. ${ }^{13,14}$ Unlike common organic vapors, ${ }^{2,5}$ where the resistance increases reversibly upon vapor exposure consistent with swelling of the films, ${ }^{15}$ one frequently observes an irreversible increase in conductivity when films are exposed to these oxidizing vapors, ${ }^{4,16}$ which is consistent with a charge-transfer/doping process. ${ }^{17,18}$ For example, $\mathrm{Cl}_{2}$ vapor is arguably the most aggressive among vapors, and there is no previous report describing an organic thin-film chemiresistor for which the signal recovers to the original baseline value after removal of $\mathrm{Cl}_{2}$. There are several reports on reversible $\mathrm{NO}_{2}$ vapor sensing using chemiresistor films of CNTs and conducting polymers, ${ }^{10,19}$ although thermal or photoirradiation is frequently required to desorb the vapor to achieve signal reversibility. ${ }^{20}$ Recent studies using graphene and reduced graphene oxide $(\mathrm{rGO})^{6,7}$ also yielded similar results. For example, although $\mathrm{NO}_{2}$ vapor was detected at $500 \mathrm{ppb}$ in ambient air, photoirradiation was required to reverse the signal. Importantly, the signal after exposure to $\mathrm{Cl}_{2}$ vapor $(750 \mathrm{ppb})$ could not be reversed even after prolonged UV irradiation and heating. ${ }^{6}$

In this report, we describe a reversible sensor for $\mathrm{Cl}_{2}$ and $\mathrm{NO}_{2}$ composed of inkjet-printed films of CNTs on cellulosic substrates (and plastics) that does not require thermal or photoirradiation for signal recovery. We demonstrate that the experimentally observed reversible signal response to $\mathrm{Cl}_{2}$ vapor is consistent with weak charge-transfer-driven p-type doping of the CNTs that does not automatically lead to irreversible covalent bond formation. We also show for the first time that cellulosics can be used as substrates for sensing chemically aggressive vapors. Even though cellulosics such as paper and cloth are ideal substrates for wearable and disposable sensors, their (supposed) instability toward highly oxidizing vapors has resulted in the use of inert plastic substrates such as polyethylene terephthalate (PET). We too noticed that while it was easier to obtain inkjet-printed films of CNTs on paper, both the signal response and recovery were very sluggish compared with PET. We now report that this is not intrinsic to cellulosics but instead is due to the various surface finishes used in commercial paper manufacture. When we used $100 \%$ acidfree paper containing no surface finishes, both $\mathrm{Cl}_{2}$ and $\mathrm{NO}_{2}$ vapors could be reversibly detected at parts per billion levels at room temperature in ambient air, opening new opportunities for the development of cheap, throwaway, lightweight vapor sensors.

The inkjet printing (IJP) method and the procedure to prepare surfactant-supported $\mathrm{CNT}^{3}$ inks are similar to those in our recently reported study on IJP of GGO films $^{6}$ and are described in detail in the Supporting Information (SI). The inkjet-printed CNT films on paper and PET were composed of a nonwoven mesh of CNT bundles that were micrometers long and $20-30 \mathrm{~nm}$ in diameter. The film thickness was 200-300 $\mathrm{nm}$, as determined by cross-sectional scanning electron microscopy (SEM) images and the optical absorbance at 550 $\mathrm{nm}$ (see the SI) as well as baseline resistance values in the 3-6 $\mathrm{M} \Omega$ range. Films on paper could be bent to a crease without significant loss of connectivity (Figure 1). On the other hand, flexibility is an issue for films on PET; for example, the thin surface coating on PET (recommended for IJP) that ensures good adhesion of inks used in cartridges tends to crack upon creasing (Figure 1).

The resistance change of inkjet-printed $\mathrm{CNT} / \mathrm{PET}$ and $\mathrm{CNT} /$ paper films upon exposure to successively decreasing concentrations of $\mathrm{NO}_{2}$ vapor is shown in Figure 2. On both PET and paper (Figure 2a,b), $\mathrm{NO}_{2}$ vapor was detected at concentrations as low as $125 \mathrm{ppb}$ in ambient air without any external aids such as a vapor concentrator. From the signal/ noise ratio, we estimate the theoretical detection limit to be $\sim 64$ ppt (see the SI). Importantly, the signal spontaneously

Received: January 13, 2012

Published: February 23, 2012 

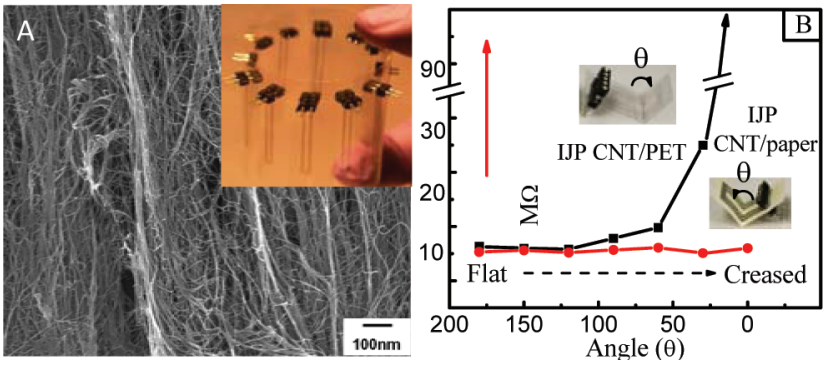

Figure 1. (A) Field-effect SEM image of inkjet-printed CNTs on PET $(\mathrm{CNT} / \mathrm{PET})$. The inset shows an array of 10 inkjet-printed CNT/ PET sensors. (B) Plot of resistance vs bending angle for CNT/PET and $\mathrm{CNT} /$ paper sensors.
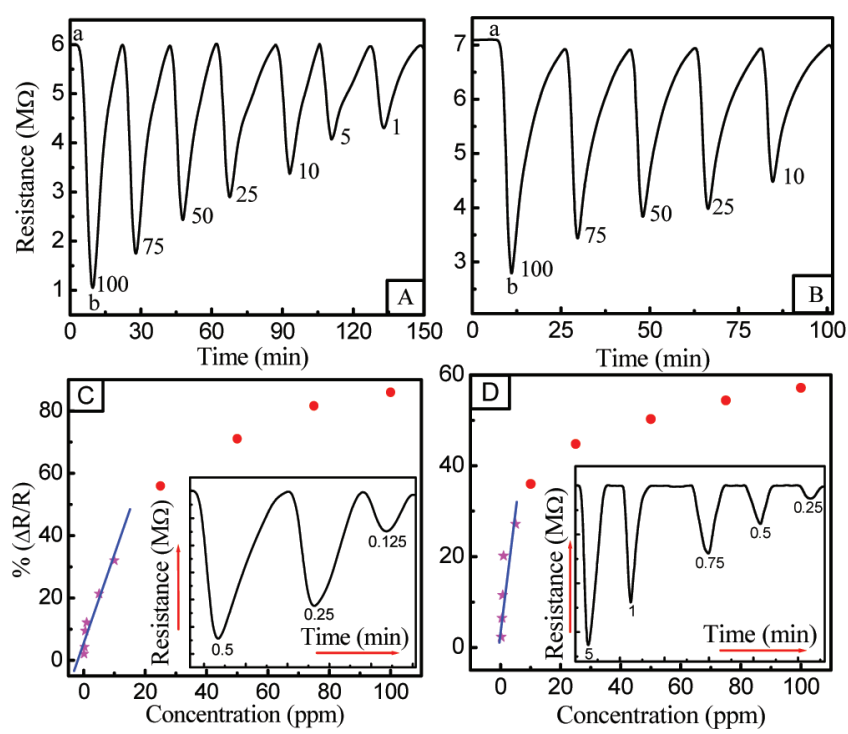

Figure 2. (A, B) Plots of resistance $(R)$ vs time for successively decreasing concentrations of $\mathrm{NO}_{2}$ vapor for inkjet-printed (A) CNT/ PET and (B) CMT/paper films. $\mathrm{NO}_{2}$ vapor was present at point "a" and removed at point " $b$ ". Numbers on valleys represent the vapor concentrations in ppm. (C, D) Plots of $\Delta R / R$ vs concentration for inkjet-printed (C) CNT/PET and (D) CNT/paper films. The insets show plots of resistance vs time at low concentrations.

recovered to the original baseline value upon removal of the $\mathrm{NO}_{2}$. This is consistent with the formation of a weak chargetransfer complex between $\mathrm{NO}_{2}$ and the CNTs that stops short of irreversible covalent bond formation. ${ }^{18}$ This is to be contrasted with the behavior of thicker dip-coated CNT/PET films, where photodesorption of $\mathrm{NO}_{2}$ was needed to achieve signal reversibility (see the SI).

The corresponding resistance changes upon exposure to $\mathrm{Cl}_{2}$ vapor are shown in Figure 3. On both substrates, $\mathrm{Cl}_{2}$ vapor was detected at concentrations as low as $500 \mathrm{ppb}$ in ambient air without the aid of a vapor concentrator. From the signal/noise ratio, we estimate the theoretical detection limit to be $\sim 163 \mathrm{ppt}$ (see the SI). On the PET substrate, the signal did not recover spontaneously when the $\mathrm{Cl}_{2}$ was removed and required photoirradiation for $\sim 3 \mathrm{~min}$, similar to the response of dipcoated CNT/PET films to $\mathrm{NO}_{2}$. However, on the paper substrate, the signal spontaneously recovered over $\sim 7 \mathrm{~min}$ in ambient air, and the sensor could be used repeatedly over multiple cycles without observable loss of function. This suggests that cellulosic substrates can meaningfully mitigate the aggressive behavior of vapors such as $\mathrm{Cl}_{2}$ toward thin organic
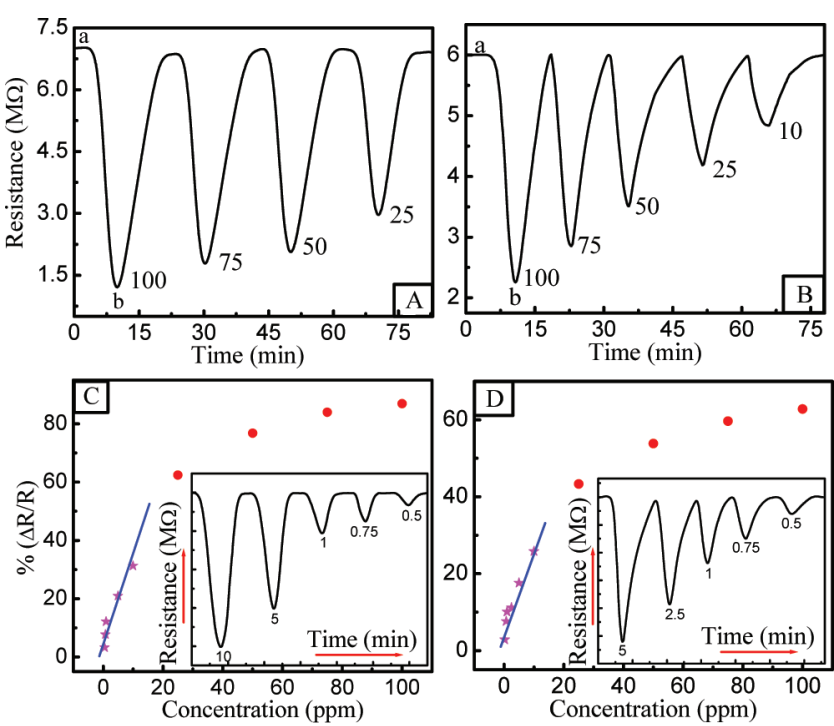

Figure 3. (A, B) Plots of resistance vs time for successively decreasing concentrations of $\mathrm{Cl}_{2}$ vapor for inkjet-printed (A) CNT/PET and (B) $\mathrm{CNT} /$ paper films. $\mathrm{Cl}_{2}$ vapor was present at point "a" and removed at point " $\mathrm{b}$ ". Numbers on valleys represent the vapor concentrations in ppm. (C, D) Plots of $\Delta R / R$ vs concentration for inkjet-printed (C) $\mathrm{CNT} / \mathrm{PET}$ and (D) CNT/paper films. The insets show plots of resistance vs time at low concentrations.

films by reducing the residence time of vapors, which could be very important in the design of real-time vapor sensors for highly oxidizing vapors. This is to be contrasted with the behavior of thicker dip-coated CNT/PET films, for which the signal response after exposure to $\mathrm{Cl}_{2}$ vapor was irreversible even upon prolonged photoirradiation (see the Figure $4 \mathrm{~d}$ inset).

The interaction of oxidizing vapors with CNTs can be viewed as evolving temporally along the following three stages: (i) An initial charge-transfer complex ${ }^{17,18}$ forms on the surface of the CNT bundles through a kinetically controlled process. The interaction is weak and fully reversible, accounting for the spontaneous signal recovery for inkjet-printed CNT/PET films with $\mathrm{NO}_{2}$ and $\mathrm{CNT} /$ paper films with $\mathrm{NO}_{2}$ and $\mathrm{Cl}_{2}$. (ii) The vapor penetrates into the interior of the $\mathrm{CNT}$ bundles and/or to the interbundle crossover points with increased residence time. ${ }^{21}$ In this case, signal recovery requires energy in the form of UV or heat treatment, which speaks to the response of dipcoated CNT/PET films toward $\mathrm{NO}_{2}$ and inkjet-printed CNT/ PET films toward $\mathrm{Cl}_{2}$. (iii) A chemical reaction with $\mathrm{CNTs}$ results in covalent bond formation, in which case the signal is not reversible, as for dip-coated CNT/PET films with $\mathrm{Cl}_{2}$. In the design of organic thin-film sensors for chemically aggressive vapors, the choice of substrate is equally as important as the active sensor element. For example, the vapor residence time is significantly reduced on porous cellulosic substrates because the vapor can desorb from all sides, as opposed to plastic substrates, where desorption is possible only from the top of the film.

Raman spectroscopy provided evidence for all three steps described above. For example, when inkjet-printed $\mathrm{CNT} /$ paper was exposed to $\mathrm{Cl}_{2}$ vapor, the graphitic $\mathrm{G}$ band of the CNTs shifted quickly by $\sim 9 \mathrm{~cm}^{-1}$ from 1574.6 to $1583.5 \mathrm{~cm}^{-1}$, consistent with p-type doping, ${ }^{17,18}$ and then recovered back to $1574.6 \mathrm{~cm}^{-1}$ within a few minutes, consistent with spontaneous vapor desorption from a paper surface as described in stage (i) above (Figure 4a). With inkjet-printed CNT/PET sensors, $\mathrm{Cl}_{2}$ sorption reached stage (ii), as evidenced by the fact that the G- 

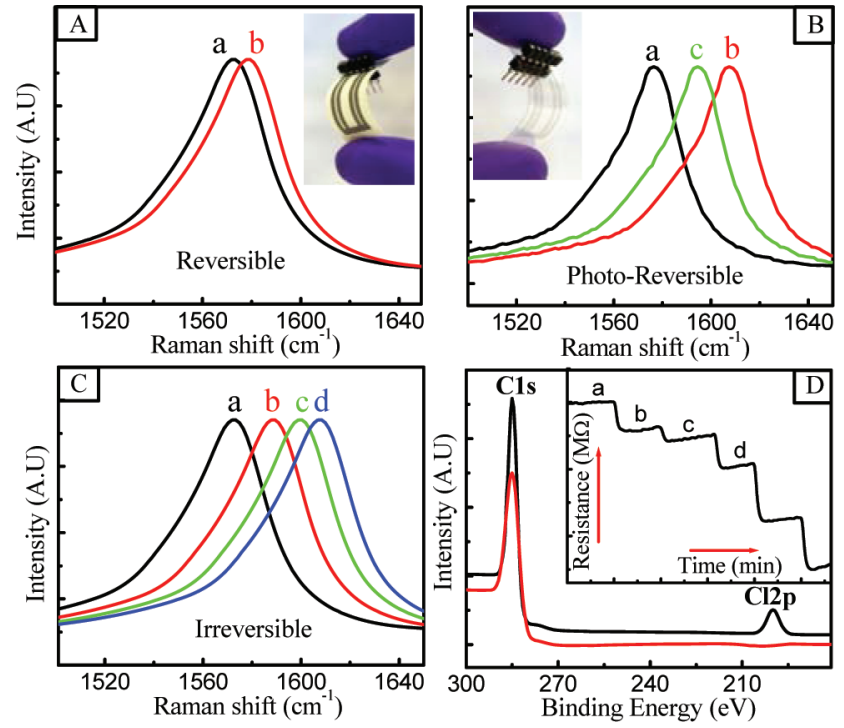

Figure 4. (A-C) G-band Raman shifts before ("a”, black) and after ("b", red) exposure to $100 \mathrm{ppm} \mathrm{Cl}_{2}$ vapor for (A) inkjet-printed CNT/ paper, where the shift is reversible; (B) inkjet-printed CNT/PET, where the shift is partially reversible upon photoirradiation (to " $c$ ", green); and (C) dip-coated CNT/PET sensors, where the peak shifts progressively and irreversibly (from "a", black, to "d", blue). (D) XPS spectrum of inkjet-printed (red) and dip-coated (black) CNT/PET films after exposure to $100 \mathrm{ppm} \mathrm{Cl}_{2}$ vapor, showing $\mathrm{C}-\mathrm{Cl}$ covalent bonds. The inset diplays the corresponding resistance response, which shows no signal recovery (irreversible sensor response).

band shifted by $\sim 34 \mathrm{~cm}^{-1}$ to $1608.6 \mathrm{~cm}^{-1}$ and did not recover spontaneously. Upon photoirradiation, it recovered only partially to $1597.1 \mathrm{~cm}^{-1}$ and remained at this new baseline value during subsequent vapor exposure and photoirradiation cycles, toggling between 1597.1 and $1608.6 \mathrm{~cm}^{-1}$ (Figure $4 \mathrm{~b}$ ). This also accounts for the unusual "first cycle" phenomenon frequently observed in CNT/PET sensors, where only the first cycle is irreversible but subsequent cycles are reversible relative to the new baseline established after the first cycle (see the SI). With dip-coated CNT/PET sensors, vapor sorption reached stage (iii), where the long residence time began to cause irreversible changes along the CNT backbone. The G band shifted by $\sim 45 \mathrm{~cm}^{-1}$ to $1619.1 \mathrm{~cm}^{-1}$ (Figure 4c), and this was accompanied for the first time by an increase in the intensity of the $\mathrm{D}$ band at $1342 \mathrm{~cm}^{-1}$ (see the SI). This defect peak is consistent with a $\mathrm{C}-\mathrm{Cl}$ covalent bond, as confirmed by a new $\mathrm{Cl} 2 \mathrm{p}$ peak in the X-ray photoelectron spectroscopy (XPS) spectrum (Figure 4d).

We also address some of the common technological challenges facing organic thin-film sensors, including selectivity, stability, baseline drift, and variation among identically fabricated sensors. The decrease in resistance observed in response to highly oxidizing CWAs should be contrasted with the increase in resistance observed when our sensors are exposed to common organic vapors (Figure 5a). In this respect, our sensors can be viewed as being selective to a class of highly oxidizing CWAs at sub-ppm levels. Importantly, the diversity of sensor responses observed with different substrates opens new opportunities for further enhancement of the selectivity (to even individual species) using classical signal-processing algorithms.

Unlike conducting polymer chemiresistor films, our inkjetprinted $\mathrm{CNT} / \mathrm{PET}$ and $\mathrm{CNT} /$ paper sensors showed no
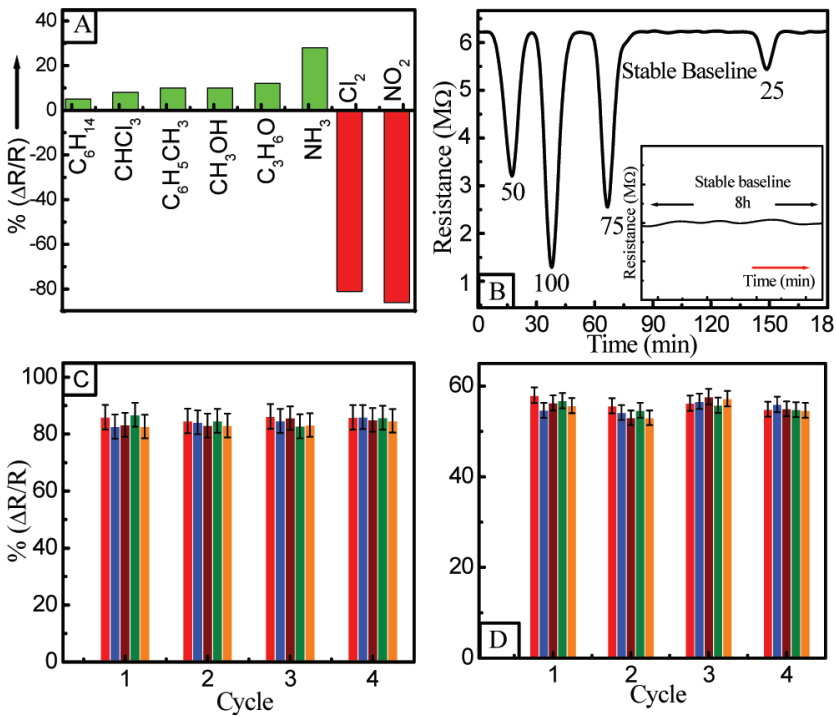

Figure 5. (A) Selectivity plot for an inkjet-printed CNT/PET film, showing an increase in resistance for common organic vapors and a decrease in resistance for $\mathrm{NO}_{2}$ and $\mathrm{Cl}_{2}$. (B) Resistance vs time profile for an inkjet-printed CNT/PET film upon exposure to random concentrations of $\mathrm{NO}_{2}$ vapor. The inset shows a stable $8 \mathrm{~h}$ baseline. (C) Plot of $\Delta R / R$ vs the number of vapor exposure cycles for five inkjet-printed CNT/PET sensors simultaneously exposed to $\mathrm{NO}_{2}$ vapor, showing a variation of $\pm 5 \%$. (D) Corresponding plots for inkjet-printed $\mathrm{CNT}$ /paper sensors, showing a variation of $\pm 3 \%$.

significant baseline drift over $\sim 8 \mathrm{~h}$ of continuous measurement at room temperature in ambient air (Figure $5 \mathrm{~b}$ ). Even upon repeated exposure to $\mathrm{NO}_{2}$ and $\mathrm{Cl}_{2}$ over multiple cycles, our sensors showed no significant deviation from the original baseline. For example, no baseline drift was observed when the inkjet-printed CNT/PET sensor was exposed to $\mathrm{NO}_{2}$ vapor at randomly chosen concentrations of 50, 100, and $75 \mathrm{ppm}$ followed by a $15 \mathrm{~min}$ baseline test and then exposure to $25 \mathrm{ppm}$ $\mathrm{NO}_{2}$ (Figure $5 b$ ).

Importantly, IJP permits us to fabricate sensor elements having a precise, preselected geometry, which significantly reduces sensor-to-sensor variation. For example, we exposed five $\mathrm{CNT} / \mathrm{PET}$ sensors simultaneously to $100 \mathrm{ppm} \mathrm{NO}_{2}$ vapor and found $\pm 5 \%$ variation in $\Delta R / R$ over four cycles (Figure $5 \mathrm{c}$ ). The corresponding variation in $\mathrm{CNT} /$ paper sensors was $\pm 3 \%$ (Figure 5d).

The robust sensor response of CNT films on cellulosics is not intrinsic to the IJP process. For example, thin CNT coatings on $100 \%$ cotton fabric obtained by simple dip-coating and air-drying could also be used to detect $\mathrm{NO}_{2}$ and $\mathrm{Cl}_{2}$. The data for $\mathrm{NO}_{2}$ in Figure 6 show that once again the baseline drift was negligible and that the $\mathrm{CNT} /$ cloth sensor not only tolerated multiple vapor exposure cycles at randomly varied concentrations but was also wash-fast and responded to $\mathrm{NO}_{2}$ vapor without loss of performance even after multiple laundering/drying cycles.

In summary, we have demonstrated for the first time (i) a lightweight, all-organic chemiresistor sensor that can detect $\mathrm{Cl}_{2}$ and $\mathrm{NO}_{2}$ vapors at room temperature; (ii) sub-ppm-level detection in ambient air; (iii) spontaneous signal recovery using cellulosic substrates; (iv) minimum sensor-to-sensor variation using IJP to control the film thickness; (v) negligible baseline drift that is unprecedented in a organic thin-film sensor; (vi) rugged sensor performance that tolerates multiple exposure 


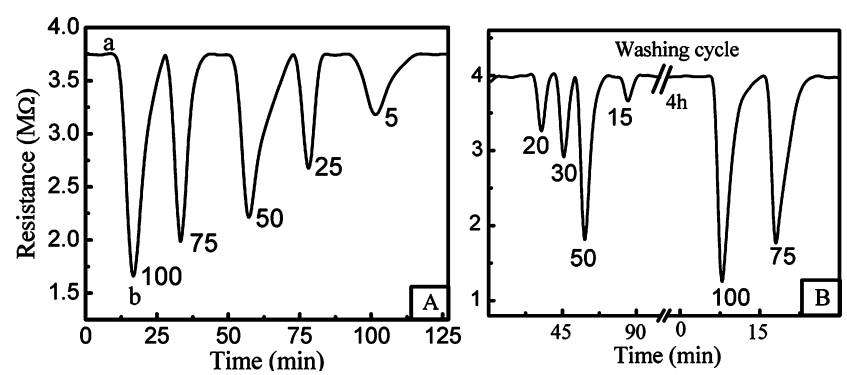

Figure 6. Resistance vs time profiles for dip-coated $\mathrm{CNT} /$ cotton (cloth) sensors exposed to (A) successively decreasing concentrations of $\mathrm{Cl}_{2}$ vapor and (B) random concentrations of $\mathrm{Cl}_{2}$ vapor and an intermediate $4 \mathrm{~h}$ laundering/drying cycle. The profiles show no baseline drift and no significant change in sensor response. Vapor was present at point "a" and removed at point " $b$ ". Numbers on valleys represent vapor concentrations in $\mathrm{ppm}$.

cycles, where the sensor is both light- and wash-fast; and (vii) high flexibility, where there is no loss of sensor performance even when the sensor is bent to a crease.

\section{ASSOCIATED CONTENT}

\section{(S Supporting Information}

Details on CNT ink formulation, IJP, sensor fabrication, sensor chamber setup, and signal acquisition and analysis, including calculation of the theoretical detection limit. This material is available free of charge via the Internet at http://pubs.acs.org.

\section{AUTHOR INFORMATION}

\section{Corresponding Author}

Sanjeev_Manohar@uml.edu

Notes

The authors declare no competing financial interest.

\section{ACKNOWLEDGMENTS}

We gratefully acknowledge funding from the University of Massachusetts Lowell, the Massachusetts Technology Collaborative (MTC)-funded Nanomanufacturing Center of Excellence (NCOE), the NSF-funded Center for High-Rate Nanomanufacturing (CHN), NSF Award 0425826, and Advanced Concepts and Technologies International.

\section{REFERENCES}

(1) (a) Kauffman, D. R.; Star, A. Angew. Chem., Int. Ed. 2008, 47, 6550. (b) Kim, S. N.; Rusling, J. F.; Papadimitrakopoulos, F. Adv. Mater. 2007, 19, 3214. (c) Zhang, T.; Mubeen, S.; Myung, N. V.; Deshusses, M. A. Nanotechnology 2008, 19, No. 332001.

(2) Li, J.; Lu, Y.; Ye, Q.; Cinke, M.; Han, J.; Meyyappan, M. Nano Lett. 2003, 3, 929.

(3) Maklin, J.; Mustonen, T.; Halonen, N.; Toth, G.; Kordas, K.; Vahakangas, J.; Moilanen, H.; Kukovecz, A.; Konya, Z.; Haspel, H.; Gingl, Z.; Heszler, P.; Vajtai, R.; Ajayan, P. M. Phys. Status Solidi B 2008, 245, 2335.

(4) Snow, E. S.; Perkins, F. K.; Robinson, J. A. Chem. Soc. Rev. 2006, 35, 790 .

(5) Wang, F.; Swager, T. M. J. Am. Chem. Soc. 2011, 133, 11181.

(6) Dua, V.; Surwade, S. P.; Ammu, S.; Agnihotra, S. R.; Jain, S.; Roberts, K. E.; Park, S.; Ruoff, R. S.; Manohar, S. K. Angew. Chem., Int. Ed. 2010, 49, 2154.

(7) (a) Fowler, J. D.; Allen, M. J.; Tung, V. C.; Yang, Y.; Kaner, R. B.; Weiller, B. H. ACS Nano 2009, 3, 301. (b) Robinson, J. T.; Perkins, F. K.; Snow, E. S.; Wei, Z.; Sheehan, P. E. Nano Lett. 2008, 8, 3137.
(8) Huang, L.; Huang, Y.; Liang, J.; Wan, X.; Chen, Y. Nano Res. 2011, 4, 675.

(9) (a) Li, W.-W.; Geng, X.-M.; Guo, Y.-F.; Rong, J.-Z.; Gong, Y.-P.; Wu, L.-Q.; Zhang, X.-M.; Li, P.; Xu, J.-B.; Cheng, G.-S.; Sun, M.-T.; Liu, L.-W. ACS Nano 2011, 5, 6955. (b) Lu, G.; Park, S.; Yu, K.; Ruoff, R. S.; Ocola, L. E.; Rosenmann, D.; Chen, J. ACS Nano 2011, 5, 1154. (c) Potyrailo, R. A.; Surman, C.; Nagraj, N.; Burns, A. Chem. Rev. 2011, 111, 7315 .

(10) (a) Dua, V.; Surwade, S. P.; Ammu, S.; Zhang, X.; Jain, S.; Manohar, S. K. Macromolecules 2009, 42, 5414. (b) Yan, X. B.; Han, Z. J.; Yang, Y.; Tay, B. K. Sens. Actuators, B 2007, 123, 107.

(11) (a) Fowler, J. D.; Virji, S.; Kaner, R. B.; Weiller, B. H. J. Phys. Chem. C 2009, 113, 6444. (b) Surwade, S. P.; Agnihotra, S. R.; Dua, V.; Manohar, S. K. Sens. Actuators, B 2009, 143, 454.

(12) (a) Baratto, C.; Sberveglieri, G.; Onischuk, A.; Caruso, B.; di Stasio, S. Sens. Actuators, B 2004, 100, 261. (b) Xia, Y.; Yang, P.; Sun, Y.; Wu, Y.; Mayers, B.; Gates, B.; Yin, Y.; Kim, F.; Yan, H. Adv. Mater. 2003, 15, 353. (c) Zhang, D.; Liu, Z.; Li, C.; Tang, T.; Liu, X.; Han, S.; Lei, B.; Zhou, C. Nano Lett. 2004, 4, 1919.

(13) Qi, P.; Vermesh, O.; Grecu, M.; Javey, A.; Wang, Q.; Dai, H.; Peng, S.; Cho, K. J. Nano Lett. 2003, 3, 347.

(14) (a) Zhao, J.; Buldum, A.; Han, J.; Lu, J. P. Nanotechnology 2002, 13, 195. (b) Sun, G.; Liu, S.; Hua, K.; Lv, X.; Huang, L.; Wang, Y. Electrochem. Commun. 2007, 9, 2436.

(15) (a) Bai, H.; Shi, G. Sensors 2007, 7, 267. (b) Im, J.; Sengupta, S. K.; Baruch, M. F.; Granz, C. D.; Ammu, S.; Manohar, S. K.; Whitten, J. E. Sens. Actuators, B 2011, 156, 715.

(16) (a) Cho, W.-S.; Moon, S.-I.; Lee, Y.-D.; Lee, Y.-H.; Park, J.-H.; Ju, B. K. IEEE Electron Device Lett. 2005, 26, 498. (b) Kong, J.; Franklin, N. R.; Zhou, C.; Chapline, M. G.; Peng, S.; Cho, K.; Dai, H. Science 2000, 287, 622.

(17) Wassei, J. K.; Cha, K. C.; Tung, V. C.; Yang, Y.; Kaner, R. B. J. Mater. Chem. 2011, 21, 3391.

(18) Zhou, W.; Vavro, J.; Nemes, N. M.; Fischer, J. E.; Borondics, F.; Kamaras, K.; Tanner, D. B. Phys. Rev. B 2005, 71, No. 205423.

(19) Yang, L.; Ouyang, M.; Li, W. J.; Han, X. IEEE Nanotechnol. 2008, 284.

(20) Surwade, S. P.; Agnihotra, S. R.; Dua, V.; Manohar, N.; Jain, S.; Ammu, S.; Manohar, S. K. J. Am. Chem. Soc. 2009, 131, 12528.

(21) (a) Chen, R. J.; Franklin, N. R.; Kong, J.; Cao, J.; Tombler, T. W.; Zhang, Y.; Dai, H. Appl. Phys. Lett. 2001, 79, 2258. (b) Peng, S.; Cho, K.; Qi, P.; Dai, H. Chem. Phys. Lett. 2004, 387, 271. 